\title{
Argument Structure of Slide Verb in English
}

\section{${ }^{2}$ I Nyoman Udayana, nyoman_udayana@unud.ac.id, Udayana University}

*Corresponding Author: manikseptianiari@gmail.com

Received Date: 31-05-2019 Accepted Date: 31-05-2019 Published Date: 31.-07.-2019

Abstract - Various languages in the world have their own systems, especially in terms of verb classification. It can determine argument in the structure. This paper is intended to analyze the interaction between syntax and semantics in terms of the argument structure of the slide verb in English. The main theory used in this study was the theory of argument structure proposed by Kim \& Sells (2008). The result of analysis showed that two kinds of slide verb: bounce and slide are intransitive and transitive verbs. The specifier (SPR) of the sentence structure functions as the agent; the Complement (COMPS) of the verb bounce serves as the patient and the COMPS of the verb slide functions as the theme.

Keywords: Slide Verb, Argument Structure, English

\section{Introduction}

Language is a system of communication in speech and writing used by people of a particular country or area (Hornby, 2010:834). According to Crystal (2003:1) English is the global language, meaning that most people use English as their language. The English signs and advertisements in a hotel or restaurant in a foreign city, for example, will be understood by people.

From the linguistic point of view, English can be analyzed in terms of phonology, morphology, syntax, and semantics. This paper focuses on syntax and semantics. Syntax is the study of sentence structure (Varga, 2010:56). A sentence consists of words from different word classes such as noun, verb, adjective, and adverb. Verb is one of the most important elements in a sentence, especially in English. According to Richards et al (1985:305), verb refers to an action or state. Generally, verb can be divided into two types; they are intransitive and transitive verbs (Dixon, 2010). A transitive verb is a verb which occurs in a transitive clause. Intransitive verb is a verb which occurs in an intransitive clause (Utami et al. 2018). The sentence with an 
intransitive verb only has one argument. Meanwhile, the sentence with a transitive verb has two or more arguments. Syntactically, a sentence structure has its core and noncore arguments (Masreng et al. 2019).

Semantic roles are the ways of classifying the arguments of predicators (Kim and Sells, 2008:43). They are agent, patient, experience, theme, benefactive, source, goal, location, and instrument. These roles are used to capture the relationship between two related sentences, for example:

1a. The cat chased the mouse

The cat chased the mouse agent patient

1b. The mouse was chased by the cat The mouse was chased by the cat patient agent

(Kim and Sells, 2008:45)

The structure of sentence (1a) is different from that of sentence (1b). Sentence (1a) is an active sentence and sentence (1b) is a passive sentence proved by the preposition by. Those sentences have the same semantic roles assigned to the Noun Phrase (NP). It can be seen that the NP the cat is the agent and the mouse is the patient. Agent is a participant that performs something. Meanwhile, patient is a participant that is being affected by what happens to it (Kim and Sells, 2008: 44). The slide verb was chosen in this study because it belongs to intransitive and transitive verbs. It consists of the verbs bounce, float, roll, and slide (Levin, 1955:133)

Based on the explanation above, this study is attempted to examine the argument structure of the slide verb in English. The data in this study were taken from a British Corpus, that is, the British National Corpus (BNC), which can be accessed from https://corpus.byu.edu/bnc/. BNC consists of a 100 million word collection of written and spoken British language. 


\section{Theoretical Framework}

The Theory of Argument Structure is used in this study. The theory is proposed by Kim and Sells (2008). Argument Structure (ARG-ST) has the elements realized by Specifier (SPR) and Complements (COMPS). Complement is a phrasal element in which a head must combine with or a head includes direct object, indirect object, predicative complement, and oblique complement (Kim and Sells, 2008:51). SPR is the first element which is realized by a subject and the rest are realized by COMPS.

According to Kim and Sells (2008:67), the argument structure of a sentence can differ based on the verb types, as illustrated by the following examples:

\section{a. Intransitive verb}

This verb does not have any COMPS as in the example John sneezed.

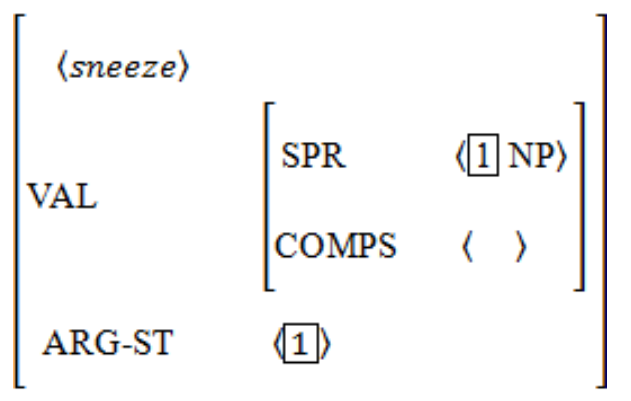

It can be seen from structure (a) that there is no COMPS element and that there is only one argument realized by the subject John.

\section{b. Linking Verb}

The linking verbs such as look, seem, remain, and feel require different complements like the category Adjective Phrase (AP) or Noun Phrase (NP) as the predicative complement. There are two arguments in this kind of verb: one is an NP as the subject and the other is any phrase $(\mathrm{XP})$ functioning as the predicate $(\mathrm{PRD}+)$ as in the example John remained a student. 


$$
\left[\begin{array}{lll}
\langle\text { remain }\rangle & & \\
\text { VAL } & {\left[\begin{array}{ll}
\text { SPR } & \text { NP }\rangle \\
\text { COMPS } & \langle 2 \text { NP }[\mathrm{PRD}+]\rangle
\end{array}\right]} \\
\text { ARG-ST } & 11,2\rangle &
\end{array}\right]
$$

\section{c. Transitive Verb}

This kind of verb requires non-predicative as the complement functioning as the direct object as illustrated in the sentence John saw Fred.

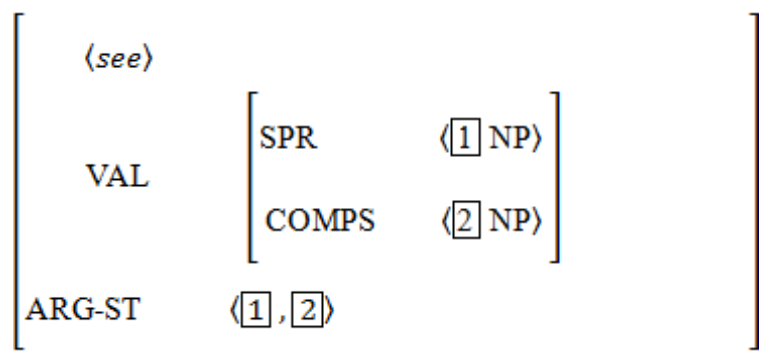

\section{d. Ditransitive Verb}

This kind of verb requires Indirect Object (IO) and Direct Object (DO), as illustrated in the sentence John taught new students English Syntax.

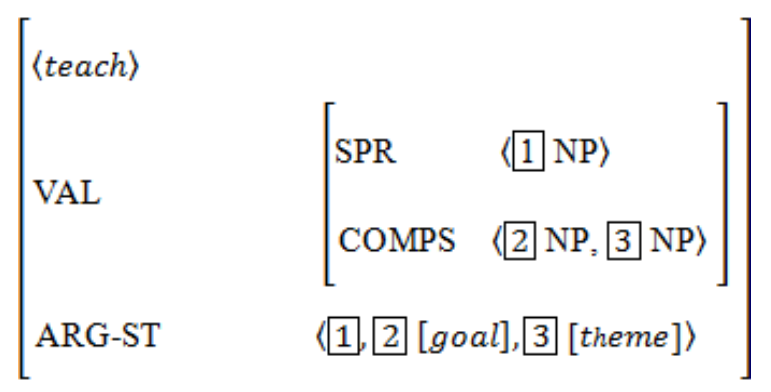

\section{e. Complex Transitive Verb}

A complex transitive verb is another type of transitive verb which has two complements, one functions as the direct object and the other as the predicative phrase (NP, AP, or VP), describing the object, as exemplified in the sentence Ad agencies call young people Generation X-ers. The NP Generation X-ers is as the predicative phrase. This verb is like linking verb that requires a predicative $([\mathrm{PRD}+]) \mathrm{XP}$ as the complement. 


\begin{tabular}{|c|c|}
\hline $\begin{array}{l}\text { e-Journal of Linguistics } \\
\text { DOAJ Indexed (Since } 15 \text { Sep 2015) }\end{array}$ & $\begin{array}{l}\text { July } 2019 \text { Vol.13 No. } 2 \text { P: 333-342 } \\
\text { //doi.org/10.24843/e-jl.2019.v13.i02.p11 }\end{array}$ \\
\hline
\end{tabular}

$\left[\begin{array}{ll}\langle\text { call }\rangle & {\left[\begin{array}{ll}\mathrm{SPR} & \langle 1 \mathrm{NP}\rangle \\ \mathrm{VAL} & \\ \text { COMPS } & \langle 2 \mathrm{NP}, 3 \mathrm{XP}\rangle\end{array}\right]} \\ \text { ARG-ST } & \langle 1,2,3[\mathrm{PRD}+]\rangle\end{array}\right]$

\section{Research Method}

This study is qualitative descriptive research using syntax and semantic approach. The data were collected using observation method and obtained from one of many online corpuses, the British National Corpus (BNC), which can be accessed from https://corpus.byu.edu/bnc/. This corpus contains 100 million words especially in British English language. This corpus is free to access. This study focuses on types of slide verb such as bounce, float, roll, and slide (Levin , 1955). The data were classified based on the types of verb in order to know the argument structure in a sentence. The theory proposed by Kim and Sells (2008) was used to analyze the data.

\section{Discussion}

According to Levin (1955), slide verbs consist of bounce, float, roll, and slide.

2a. We can bounce the ball (BYU-BNC, A woman of style)

The verb bounce in sentence (a) is categorized as a transitive verb. This verb is modified by the modal verb can. In this sentence, there are two arguments which serve as SPR of the subject we and COMPS in the NP the ball as in (2b). 
2b. $\left[\begin{array}{lll}\langle\text { bounce }\rangle & & \\ \text { VAL } & {\left[\begin{array}{ll}\text { SPR } & \langle 1 \mathrm{NP}\rangle \\ \text { COMPS } & \langle 2 \mathrm{NP}\rangle\end{array}\right]} \\ \text { ARG-ST } & \langle 1,2\rangle & \end{array}\right]$

In sentence (2a), the SPR we is the agent because there is one participant that performs something. Furthermore, the COMPS the ball is the patient as it is affected by what happens to it (Kim and Sells, 2008:44).

3a. He will bounce back (BYU-BNC, Liverpool Daily Post and Echo)

In sentence (3a) the Verb Phrase (VP) will bounce is followed by the adverb back. Unlike sentence (2a), sentence (3a) is an intransitive verb. This verb follows the NP he as the subject, meaning that this sentence only has one argument categorized as the agent. The argument structure of sentence (3a) can be illustrated as follows.

$3 b$.

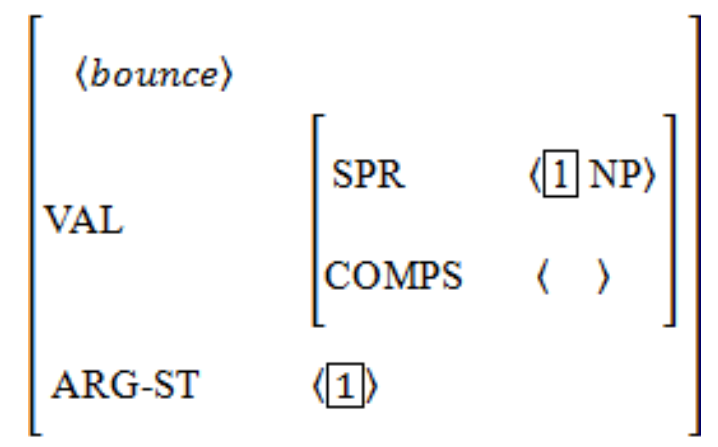

4a. Miniature water lilies float on a tiny pond (BYU-BNC, Ideal Home)

The verb float in sentence (4a) is an intransitive verb in which there is only one argument which serves as the agent of the argument structure. The verb is followed by the 
Prepositional Phrase (PP) on a tiny pond. The semantic structure of the verb can be illustrated in (4b).

$4 b$.

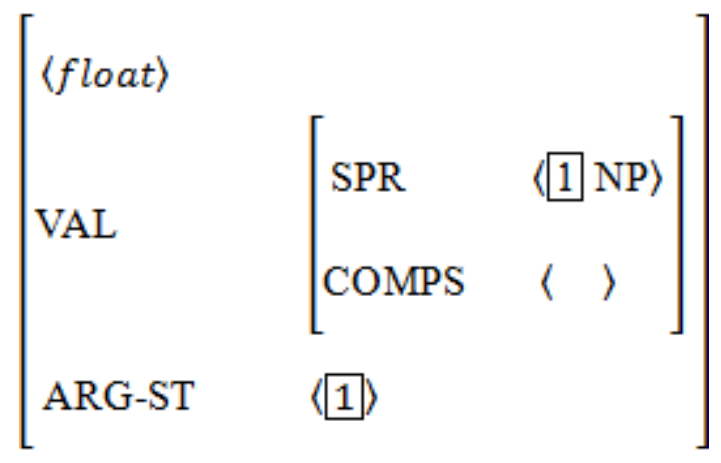

5a. It would roll around on the carpet (BYU-BNC, Catlore)

Like sentence (4a), the verb roll is an intransitive verb that is followed by the PP around the carpet. The agent it in sentence (5a) means that there is something that would be rolled by someone around on the carpet. The argument structure of this verb is illustrated in $(5 b)$

$5 b$.

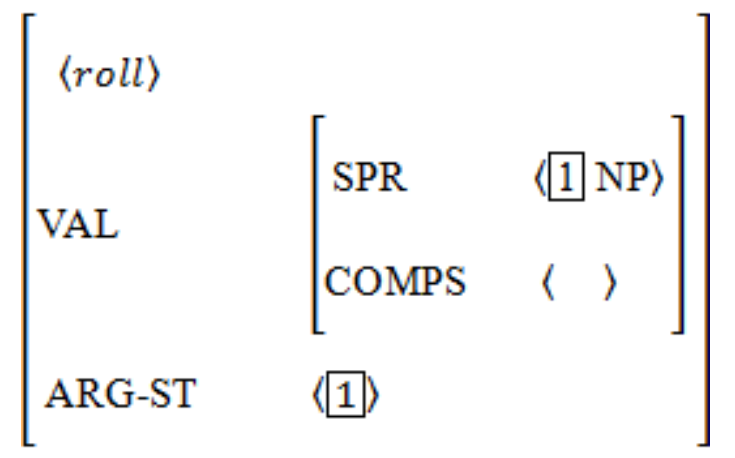

6a. I slide a bowl of fruit onto the table (BYU-BNC, Underground)

The verb slide in sentence (6a) is a transitive verb. There are two arguments in the sentence; they are the subject $I$ as SPR and the other is NP a bowl of fruit as COMPS. 
From the semantic role point of view, SPR in the sentence is categorized as an agent because it is a participant that does something and COMPS is a theme because its position can be changed (Kim and Sells, 2008:44). The argument structure of the verb in sentence (6a) can be illustrated in (6b).

$6 b$.

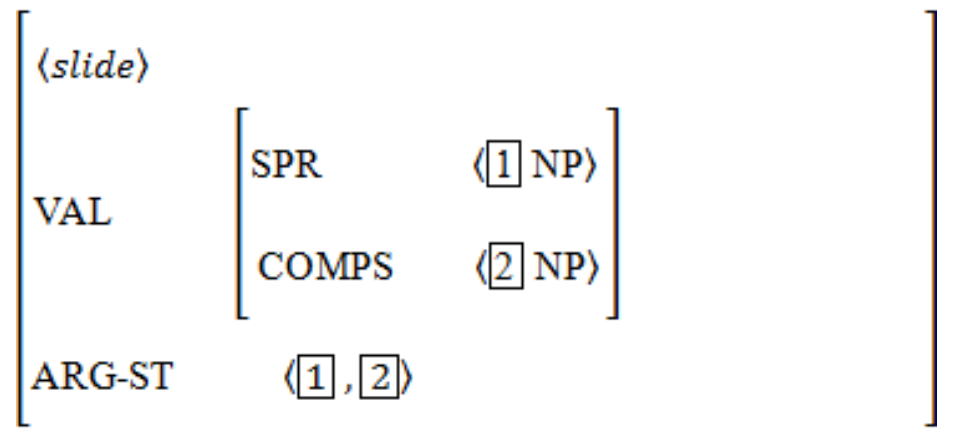

7a. We could slide together (BYU-BNC, Underground)

In sentence (7a), the verb slide is an intransitive verb. The reason is that there is only one argument, namely the agent, as shown by the argument structure (7b). This verb is followed by the adverb together.

$7 b$.

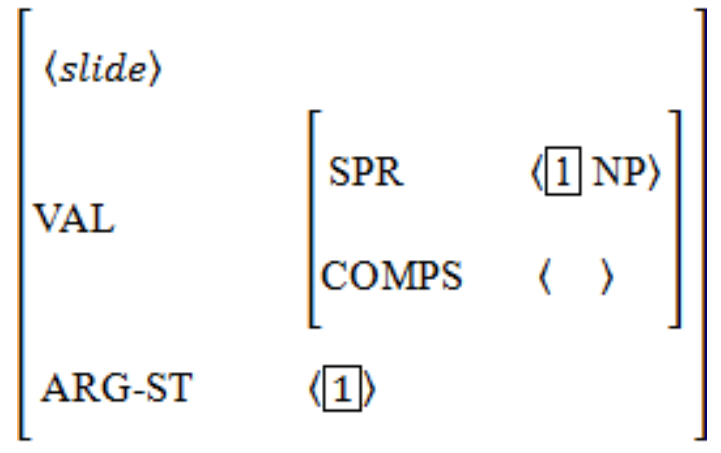




\section{Novelties}

The novelties of this study are that (1) the data were obtained from the British online corpus; British National Corpus (BNC) and (2) the Argument Structure theory proposed by Kim and Sells (2008) was applied in this study.

\section{Conclusion}

Based on the explanation above, it can be concluded that slide verbs belong to intransitive and transitive verbs. The verbs bounce and slide can be used as intransitive and transitive verbs. Meanwhile, the verbs float and roll are used as intransitive verbs. Furthermore, SPR in those sentences functions as the agent. The COMPS of the verb bounce serve as the patient and the COMPS of the sentence structure with the verb slide serve as the theme.

\section{References}

Crystal, David. 2003. English as a Global Language Second Edition. Cambridge: Cambridge University Press.

Hornby, A.S. 2010. Oxford Advanced Learner's Dictionary Eighth Edition. Oxford: Oxford University Press.

Kim, Jong-Bok and Sells, Peter. 2008. English Syntax: An Introduction. Stanford: CSLI Publications.

Levin, Beth. 1955. English Verb Classes and Alternations. London: The University of Chicago Press.

Masreng, Robert, et al. CAUSATIVITY AND ALTERNATION ME-KAN / -I IN INDONESIAN. eJournal of Linguistics, [S.1.], p. 32-42, jan. 2019. ISSN 2541-5514. Available at: <https://ojs.unud.ac.id/index.php/eol/article/view/45946>. Date accessed: 04 mar. 2019.

Richards, et al. 1985. Longman Dictionary of Applied Linguistics. England: Longman.

Utami, Ni Made Verayanti, et al. THE ANALYSIS OF INDONESIAN TRANSITIVE AND INTRANSITIVE VERBS FOUND IN THE TRANSLATION OF POSSUM MAGIC - AN AUSTRALIAN CLASSIC BY BIPA STUDENTS OF LA DENPASAR. e-Journal of Linguistics, [S.1.], p. 79--87, july 2018. ISSN 2541-5514. Available at: <https://ojs.unud.ac.id/index.php/eol/article/view/40696>. Date accessed: 03 mar. 2019.

Varga, László. 2010. Introduction to English Linguistics: A Companion to the Seminar. Budapest: Eötvös Loránd University. 


\begin{tabular}{|c|c|}
\hline $\begin{array}{l}\text { e-Journal of Linguistics } \\
\text { DOAJ Indexed (Since } 15 \text { Sep 2015) }\end{array}$ & July 2019 Vol.13 No. 2 P: 333-342 \\
\hline e-ISSN: $2442-7586$ p-ISSN: 2541-5514 & https://ojs.unud.ac.id/index.php/eol/ \\
\hline
\end{tabular}

\section{Acknowledgements}

Thanks and the deepest gratitude are expressed to the board of examiners:Prof. Dr. I Nyoman Suparwa, M.Hum., Dr. Ni Luh Ketut Mas Indrawati, TEFL., M.A., and Dr. Made Sri

Satyawati, S.S., M.Hum for their critical comments and suggestions for the improvement this paper. 